\section{Psychological Medicine}

cambridge.org/psm

\section{Original Article}

Cite this article: Sallis HM, Davey Smith G, Munafò MR (2019). Cigarette smoking and personality: interrogating causality using Mendelian randomisation. Psychological Medicine 49, 2197-2205. https://doi.org/ $10.1017 /$ S0033291718003069

Received: 4 January 2018

Revised: 19 June 2018

Accepted: 25 September 2018

First published online: 25 October 2018

\section{Key words:}

Extraversion; Mendelian randomisation; neuroticism; personality traits; smoking behaviours

Author for correspondence: Hannah M. Sallis, E-mail: hannah.sallis@ bristol.ac.uk (c) Cambridge University Press 2018. This is an Open Access article, distributed under the terms of the Creative Commons Attribution licence (http://creativecommons.org/licenses/ by/4.0/), which permits unrestricted re-use, distribution, and reproduction in any medium, provided the original work is properly cited.

\section{CAMBRIDGE} UNIVERSITY PRESS

\title{
Cigarette smoking and personality: interrogating causality using Mendelian randomisation
}

\author{
Hannah M. Sallis ${ }^{1,2,3,4}$, George Davey Smith ${ }^{1,3}$ and Marcus R. Munafò ${ }^{1,2}$
}

${ }^{1}$ MRC Integrative Epidemiology Unit at the University of Bristol, Bristol, UK; ${ }^{2}$ UK Centre for Tobacco and Alcohol Studies, School of Psychological Science, University of Bristol, Bristol, UK; ${ }^{3}$ Population Health Sciences, Bristol Medical School, University of Bristol, Bristol, UK and ${ }^{4}$ Centre for Academic Mental Health, Population Health Sciences, Bristol Medical School, University of Bristol, Bristol, UK

\begin{abstract}
Background. Despite the well-documented association between smoking and personality traits such as neuroticism and extraversion, little is known about the potential causal nature of these findings. If it were possible to unpick the association between personality and smoking, it may be possible to develop tailored smoking interventions that could lead to both improved uptake and efficacy.

Methods. Recent genome-wide association studies (GWAS) have identified variants robustly associated with both smoking phenotypes and personality traits. Here we use publicly available GWAS summary statistics in addition to individual-level data from UK Biobank to investigate the link between smoking and personality. We first estimate genetic overlap between traits using LD score regression and then use bidirectional Mendelian randomisation methods to unpick the nature of this relationship.

Results. We found clear evidence of a modest genetic correlation between smoking behaviours and both neuroticism and extraversion. We found some evidence that personality traits are causally linked to certain smoking phenotypes: among current smokers each additional neuroticism risk allele was associated with smoking an additional 0.07 cigarettes per day (95\% CI $0.02-0.12, p=0.009$ ), and each additional extraversion effect allele was associated with an elevated odds of smoking initiation (OR 1.015, 95\% CI 1.01-1.02, $p=9.6 \times 10^{-7}$ ).

Conclusion. We found some evidence for specific causal pathways from personality to smoking phenotypes, and weaker evidence of an association from smoking initiation to personality. These findings could be used to inform future smoking interventions or to tailor existing schemes.
\end{abstract}

\section{Introduction}

There is a well-documented association between smoking behaviours and personality traits such as neuroticism and extraversion (Terracciano and Costa, 2004; Malouff et al., 2006; Munafò et al., 2007; Hakulinen et al., 2015), and with associated mental health outcomes such as major depressive disorder (MDD) (Munafò and Araya, 2010; Fluharty et al., 2017). However, given that much of these data come from observational studies, it is difficult to establish whether these relationships are causal. It is possible that the observed associations could be due to confounding, and if a true causal relationship does exist, the direction of effect is unknown.

Understanding these relationships is important for public health and policy. The World Health Organisation (WHO) now recognises smoking as one of the leading modifiable risk factors for disability, disease and death (World Health Organisation, 2002). As a result, if it were possible to unpick the association between personality and smoking, it may be possible to develop more tailored smoking interventions, which could lead to both improved uptake and efficacy. For example, existing smoking cessation schemes could be tailored according to personality traits (Cherry and Kiernan, 1976), with individuals allocated a different number of sessions or intensity of intervention according to their level of neuroticism.

Neuroticism and extraversion are two of the main components of personality. The former reflects emotional instability, stress vulnerability and proneness to anxiety (Kendler et al., 1993). Higher neuroticism has been linked to anxiety and MDD, with some evidence of shared genetics and a causal link between neuroticism and MDD onset (Neale et al., 2005; Gale et al., 2016). Although levels of neuroticism are higher among smokers, the evidence that neuroticism is linked with smoking initiation is inconsistent, with one meta-analysis suggesting that neuroticism is linked with relapse to smoking among former smokers (Hakulinen et al., 2015) rather than smoking initiation. In contrast, extraversion is characterised by tendencies such as liveliness and assertiveness of an individual and the level of ease and 


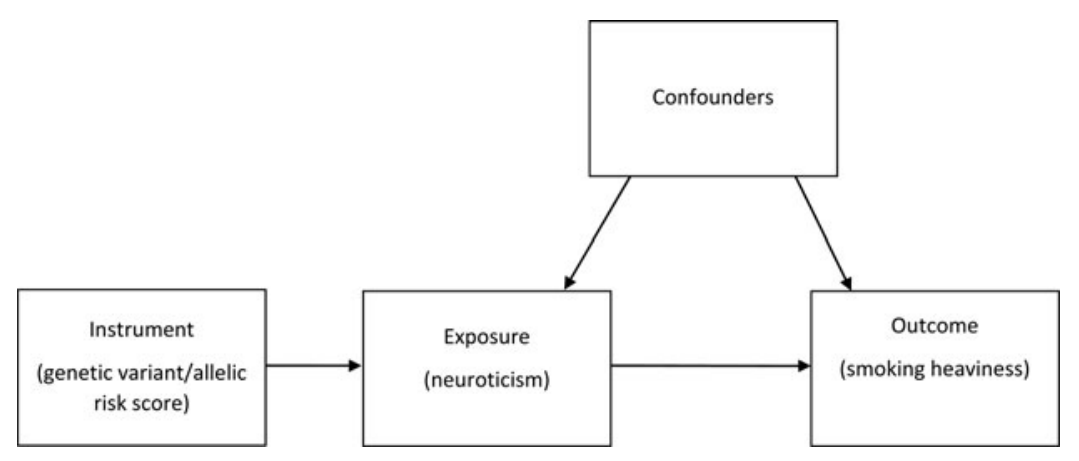

Fig. 1. Directed acyclic graph illustrating Mendelian randomisation In this model, allelic risk scores associated with neuroticism are calculated and used to assess the association of neuroticism with smoking heaviness.

enjoyment of social interactions (Kendler et al., 1993; van den Berg et al., 2016). There is some suggestion in the literature that high levels of extraversion are associated with greater rates of smoking initiation, and lower rates of smoking cessation (Hakulinen et al., 2015).

With traditional epidemiological methods, it is difficult to establish causality using observational data due to issues such as reverse causation and confounding. Mendelian randomisation (MR) is a technique that enables us to assess causal effects in observational datasets using genetic instrumental variables (Sallis et al., 2014). MR can be thought of as analogous to a randomised controlled trial, with the genetic variants used as proxies or markers of randomisation into a group that later goes on to encounter more of a risk factor, such as smoking (Fig. 1). The MR principle relies on approximations of Mendel's first and second laws of segregation and independent assortment (Davey Smith, 2011). Assuming the genetic variants are not associated with the outcome other than through the risk factor of interest, we can make inferences about the causal direction of any association between the risk factor and the outcome (Davey Smith and Ebrahim, 2003). If the underlying assumptions of MR are satisfied, the resulting effect estimates should be free from the problems of confounding and reverse causality to which observational epidemiology is prone (Sallis et al., 2014), although interpretation of such estimates requires careful consideration (Holmes et al., 2017).

Previous work using MR have yielded no strong evidence of a causal relationship in the direction of smoking to depression (Taylor et al., 2014). We therefore hypothesised that if a causal association with neuroticism exists, it is more likely to act from neuroticism to smoking. Recent genome-wide association studies (GWAS) have identified variants robustly associated with a number of smoking phenotypes (Tobacco and Genetics Consortium, 2010) and with personality traits (Okbay et al., 2016; Lo et al., 2017). Here we use these publicly available GWAS summary statistics in addition to individual-level data from UK Biobank (UKB) (Sudlow et al., 2015) in a bidirectional analysis to investigate whether there appears to be a causal link between smoking and personality.

\section{Methods and measures}

\section{Genetic instruments}

\section{Smoking behaviour}

Three smoking behaviours were investigated: initiation, heaviness and cessation. For each of the smoking phenotypes, a single variant identified by the Tobacco and Genetics (TAG) consortium (2010) was used as a genetic instrument for this behaviour. These were as follows: the rs6265 variant in the BDNF gene identified for smoking initiation, the rs16969968 variant in the CHRNA5 gene for smoking heaviness among past and current smokers and the rs3025343 variant in the $D B H$ gene for smoking cessation. For each phenotype, the effect allele was that which corresponded to an increase in the relevant smoking behaviour.

\section{Personality}

Eleven independent variants associated with neuroticism were reported by Okbay et al. (2016). Of the original variants, five of these were unavailable in the TAG smoking data. Proxies were identified for four of these single-nucleotide polymorphisms (SNPs) using SNIPA (Arnold et al., 2015) $\left(r^{2}>0.85\right)$. A complete list of variants included in the neuroticism instrument can be found in online Supplementary Table S1. Five independent variants associated with extraversion were identified using data from the Genetics of Personality Consortium (GPC) and 23andMe (Lo et al., 2017). Of these variants, three variants were unavailable in the TAG summary statistics. Using SNIPA, we identified a proxy for one of these variants (online Supplementary Table S1). There was no overlap between the variants included in any of the smoking or personality instruments.

The amount of variance explained by each of these instruments in UKB is reported in online Supplementary Table S2.

\section{Data sources}

Summary statistics from several GWASs were used for two-sample $\mathrm{MR}$ analyses, while individual-level data from UKB were used for one-sample analyses.

\section{GWAS summary statistics}

Publicly available summary statistics are available for recent genome-wide analyses of both smoking phenotypes and personality traits. GWAS summary statistics for smoking initiation, cessation and heaviness were published by the TAG consortium (2010). Summary statistics for personality traits were taken from two recent GWASs of neuroticism and extraversion (Okbay et al., 2016; Lo et al., 2017).

\section{UK Biobank}

UKB has collected phenotypic information on around 500000 participants, with genotyping available on approximately 337 106 unrelated Europeans, exclusion criteria and quality control measures are described in detail elsewhere (Bycroft et al., 2017; Mitchell et al., 2017). An interim release of genetic data was made available in 2015 for a subset of the cohort. This subset was included in the neuroticism GWAS and contained approximately 114780 European individuals (Sudlow et al., 2015). 
Smoking status was defined as ever (consisting of current and former smokers) or never smoker according to responses given at the initial assessment visit in UKB. Smoking heaviness was derived for former and current smokers based on responses to 'number of cigarettes currently smoked daily' at the initial assessment. For former smokers, this question related to number of cigarettes previously smoked on a daily basis.

Neuroticism scores were derived from a number of neurotic behaviour domains measured at the initial assessment visit. These scores were externally derived by Smith et al. (2013) and are available for use by researchers accessing the UKB resource. Scores range from 0 to 12 with a higher score corresponding to a greater number of neurotic behaviours. There was no direct measure of extraversion in UKB, so analyses of this trait were restricted to those using the genetic instrument for extraversion.

Unweighted polygenic risk scores for neuroticism and extraversion were calculated for each individual in UKB based on the number of copies of each risk allele carried by an individual; this ranged from 0 to 2 for each SNP. The neuroticism risk score ranged from 1 to 19 and corresponded to the number of neuroticism increasing alleles per individual. A risk score was calculated similarly for extraversion and ranged from 0 to 6 . Although weighted scores can give a more precise effect estimate, the neuroticism GWAS included the interim release of UKB within the discovery sample (Okbay et al., 2016; Wray et al., 2018). Risk scores should use weightings derived from independent samples to avoid introducing bias into the effect estimates (Hartwig and Davies, 2016).

\section{Statistical analysis}

\section{Genetic correlation}

In a first step, GWAS summary statistics were used to estimate the genetic correlation of smoking initiation with both neuroticism and extraversion. LD score regression was performed (without constraining the intercept) using the GWAS summary statistics to assess the amount of genetic overlap between the two traits. In order to estimate genetic correlation between personality measures and additional smoking phenotypes of smoking heaviness and cessation, summary statistics for the personality GWAS would need to be stratified by smoking status. Although the original GWAS summary statistics were not available stratified by smoking status, it was possible to estimate these genetic correlations using the individual-level data available in UKB. Genomewide complex trait analysis (GCTA) software (Yang et al., 2011) was used to estimate genetic correlation for each smoking phenotype using data from UKB.

\section{Two-sample MR using summary statistics}

Bidirectional two-sample MR analyses were performed using the genetic instruments described above. Effect estimates and standard errors (S.E.S) were extracted for each variant from the relevant GWAS results and used to estimate inverse variance weighted (IVW) effect estimates. For the neuroticism instrument which incorporated multiple SNPs, we performed a number of sensitivity analyses. Effect estimates and s.E.s were extracted from the original GWAS results as described above and MR-Egger (Bowden et al., 2015) and weighted median regression (Bowden et al., 2016) approaches were performed. These are complementary approaches: MR-Egger calculates effect estimates adjusted for horizontal pleiotropy (under the assumption that other conditions of MR-Egger are not violated) (Bowden et al., 2015), while weighted median calculates effects which are robust as long as 50\% or more of the statistical weight within an analysis comes from valid instruments (Bowden et al., 2016). We also calculated Rücker's Q to investigate heterogeneity in the SNP-exposure associations (Bowden et al., 2017). Neuroticism and extraversion GWAS results were not stratified by smoking status. As a result, when using summary statistics, analyses in the direction of smoking to personality were restricted to smoking initiation only.

\section{One-sample analyses using individual-level data}

Further analyses were performed using data from UKB. These analyses estimated the association between the genetic instrument and the outcome as there was no measure of extraversion in the UKB sample, and the neuroticism GWAS included data from UKB which could bias the two-sample IVW estimates. Within UKB, it was possible to stratify participants according to smoking status. Therefore, in addition to smoking initiation, we also investigated the association between both smoking heaviness and cessation with personality. These analyses were adjusted for the top 10 principal components as well as genotype array.

\section{Sensitivity analyses}

We restricted analyses using the neuroticism risk score to participants who were not included in the interim release of the genetic data, and who were therefore not included in the discovery sample. We also calculated IVW estimates in UKB using the neuroticism instrument for comparison with the effect estimates from the two-sample analysis.

\section{Results}

\section{Genetic correlation}

LD score regression using summary statistics from the TAG consortium GWAS of smoking initiation and the Okbay et al. neuroticism GWAS suggested evidence of a modest genetic correlation between the two traits $\left(r_{\mathrm{G}}=0.124\right.$, S.E. $\left.=0.05, p=0.008\right)$. There was also evidence of a larger genetic correlation between extraversion and smoking initiation $\left(r_{\mathrm{G}}=0.288\right.$, s.E. $=0.01, p=0.001$; Table 1). We used GCTA software to calculate genetic correlation using individual-level data from UKB. There was evidence of genetic correlation between neuroticism and smoking heaviness among both current $\left(r_{\mathrm{G}}=0.248\right.$, S.E. $\left.=0.12, p=0.013\right)$ and former smokers $\left(r_{\mathrm{G}}=0.220\right.$, s.E. $\left.=0.06, p=1.8 \times 10^{-5}\right)$. We found evidence of a negative genetic correlation between smoking cessation and neuroticism $\left(r_{\mathrm{G}}=-0.314\right.$, s.E. $=0.15, p=0.002$; Table 1$)$.

\section{Observational association between neuroticism and smoking behaviours}

Data on smoking status and neuroticism were available from UKB. A total of 389770 participants had data available on both smoking and neuroticism, with genotyping available on 273516 of these after applying QC measures. There was strong evidence of an observational association between neuroticism and smoking status in both the entire UKB sample and when restricting to those with genotyping data. Mean neuroticism scores were higher among former $(4.22$, S.D. $=3.3)$ and current smokers (4.66, S.D. $=3.5$ ) than non-smokers $(3.89$, S.D. $=3.2, p<0.001)$. We found evidence of an association between neuroticism and cigarettes smoked per day with heavier smokers reporting higher neuroticism scores $(\beta=0.02,95 \%$ CI $0.02-0.03, p<0.001)$. 
Table 1. Genetic correlation between smoking phenotypes and personality traits using GWAS summary statistics and individual-level data from UK Biobank

\begin{tabular}{lll}
\hline & $r_{\mathrm{G}}$ (s.E.) & $p$ value \\
\hline Neuroticism and smoking initiation $^{\mathrm{a}}$ & $0.124(0.05)$ & 0.008 \\
\hline Extraversion and smoking initiation $^{\mathrm{a}}$ & $0.288(0.01)$ & 0.001 \\
\hline $\begin{array}{l}\text { Neuroticism and smoking heaviness } \\
\text { (current smokers) }^{\mathrm{b}}\end{array}$ & $0.248(0.12)$ & 0.013 \\
\hline $\begin{array}{l}\text { Neuroticism and smoking heaviness } \\
\text { (former smokers) }^{\mathrm{b}}\end{array}$ & $0.220(0.06)$ & $1.8 \times 10^{-5}$ \\
\hline Neuroticism and smoking cessation $^{\mathrm{b}}$ & $-0.314(0.15)$ & 0.002 \\
\hline
\end{tabular}

${ }^{\mathrm{a}}$ Genetic correlation estimates for smoking initiation were generated using GWAS summary statistics.

${ }^{\mathrm{b}}$ Estimates for smoking heaviness and cessation were generated using individual-level data from UK Biobank.

\section{Effects of smoking on personality traits}

\section{Neuroticism}

We first used two-sample MR to investigate the effect of smoking initiation on personality using publicly available GWAS summary statistics. This found no clear evidence of an effect of smoking initiation on neuroticism when using rs6265 as an instrument for smoking initiation $(\beta=-0.032,95 \% \mathrm{CI}-0.16$ to $0.09, p=0.617$; Table 2). A one-sample approach was also used to investigate the association between each smoking behaviour and neuroticism in UKB. This found weak evidence of an effect, with each copy of the smoking initiation risk allele associated with a lower neuroticism score $(\beta=-0.023,95 \%$ CI -0.045 to $-0.001, p=0.037$; Table 2).

The genetic variant rs16969968 was used as a proxy for smoking heaviness in UKB. Despite strong evidence of an observational association between smoking heaviness and neuroticism, we found no robust evidence of a causal effect of the rs16969968 variant for smoking heaviness on neuroticism among either former or current smokers (Table 2). Using the rs3025343 variant as a proxy for smoking cessation found no strong evidence of an effect of smoking cessation on neuroticism $(\beta=0.029,95 \% \mathrm{CI}-0.01$ to $0.07, p=0.161$; Table 2) in UKB.

\section{Extraversion}

When using two-sample MR to look at the association between extraversion and smoking, there was some indication that smoking initiation was associated with greater extraversion $(\beta=0.198$, $95 \%$ CI -0.03 to $0.42, p=0.084$; Table 2 ), although the evidence for this was weak. There was no relevant measure of extraversion in UKB, so we were unable to look at the effect of the genetic variant for smoking initiation on extraversion using individual-level data.

\section{Effects of personality traits on smoking}

\section{Smoking initiation}

Two-sample MR using summary statistics found no clear evidence for an effect of neuroticism on smoking initiation either when using an IVW approach (OR 1.165, 95\% CI 0.71-1.91, $p=0.499$; Table 3 ) or when performing sensitivity analyses (online Supplementary Tables S3 and S4). Among the UKB participants, there was no robust evidence for an effect of the neuroticism risk score on smoking initiation (OR 1.000, 95\% CI 0.997-1.003, $p=0.980$; Table 3). When looking at the effect of extraversion on smoking initiation, we found no strong evidence of an effect when using a two-sample approach (OR 1.733, 95\% CI $0.37-8.23, p=0.268$ ). However, this may be due to a lack of power. The direction of effect was consistent within the UKB sample, where there was strong evidence of an association. Each additional extraversion allele was associated with 1.5\% higher odds of ever smoking (OR 1.015, 95\% CI 1.01-1.02, $p=9.6 \times$ $10^{-7}$; Table 3).

\section{Smoking heaviness}

Using an IVW approach, we found no clear evidence for an effect of neuroticism on smoking heaviness $(\beta=0.050,95 \% \mathrm{CI}-4.11$ to $4.21, p=0.979$; Table 3). However, MR-Egger suggested some evidence of horizontal pleiotropy $(\beta=-0.500,95 \%$ CI -0.93 to $-0.07, p=0.026$; online Supplementary Tables S3 and S4) and the bias-adjusted estimate suggested some evidence of an association between neuroticism and greater smoking heaviness $(\beta=$ $22.55,95 \%$ CI 2.82-42.27, $p=0.027)$. We also looked at this association in UKB when stratifying according to smoking status and found some evidence of an association. Among current smokers, the neuroticism risk score was associated with greater smoking heaviness $(\beta=0.068,95 \%$ CI $0.02-0.12, p=0.009$; Table 3$)$. In this analysis, each additional neuroticism risk allele was associated with smoking an extra 0.07 cigarettes per day. We found no robust evidence for an effect of extraversion on smoking heaviness either when using a two-sample MR approach $(\beta=0.017,95 \%$ CI -16.33 to $16.37, p=0.997$; Table 3 ) or when stratifying on smoking status and investigating this association in UKB. This remained the case among both former $(\beta=-0.021,95 \%$ CI -0.08 to $0.04, p=0.519)$ and current smokers $(\beta=-0.038,95 \%$ CI -0.13 to $0.05, p=0.419$; Table 3 ).

\section{Smoking cessation}

When using two-sample MR with summary statistics, we found no robust evidence for an effect of neuroticism on smoking cessation when using the IVW approach, or when performing sensitivity analyses (Table 3, online Supplementary Tables S3 and S4). This remained the case when looking within UKB (OR 0.997, $95 \%$ CI $0.99-1.00, p=0.272$; Table 3 ). There was no strong evidence for an effect of extraversion on smoking cessation when using two-sample MR with summary statistics (OR 0.586, 95\% CI $0.07-4.76, p=0.387$; Table 3 ). When restricting our analyses to current and former smokers within UKB, we found weak evidence of an effect and the direction of effect was consistent with that shown in the two-sample analysis. Each additional increase in extraversion risk allele was associated with $1.1 \%$ lower odds of smoking cessation (95\% CI 0.98-1.00, $p=0.057$; Table 3).

\section{Sensitivity analyses}

Analyses involving neuroticism were also performed restricting to participants whose genetic data were not included in the interim release of UKB data. Full results are reported in online Supplementary Table S5. Results remained largely consistent with those calculated in the full sample. In this subset, the strength of evidence for the effect of neuroticism on smoking heaviness was weakened (current smokers: $\beta=0.053,95 \% \mathrm{CI}$ -0.01 to $0.12, p=0.120)$. However, the effect size remained consistent, so this may be due to a lack of power in this smaller sample.

IVW effect estimates were calculated for the effect of neuroticism on smoking behaviours using the full release of UKB (online 
Table 2. Effect of smoking on personality traits using one- and two-sample MR

\begin{tabular}{|c|c|c|c|c|c|c|c|c|}
\hline Exposure & Outcome & Sample & Instrument & $\begin{array}{l}\text { Smoking } \\
\text { status }\end{array}$ & $\beta^{\mathrm{a}}$ & $95 \% \mathrm{Cl}$ & $\begin{array}{c}p \\
\text { value }\end{array}$ & $N$ \\
\hline \multirow[t]{4}{*}{$\begin{array}{l}\text { Smoking } \\
\text { initiation }\end{array}$} & Neuroticism & $\begin{array}{l}\text { GWAS } \\
\text { summary } \\
\text { statistics }\end{array}$ & rs6265 & All & -0.032 & -0.16 to 0.09 & 0.617 & 170.911 \\
\hline & & UK Biobank & & All & -0.023 & -0.045 to -0.001 & 0.037 & 274230 \\
\hline & Extraversion & $\begin{array}{l}\text { GWAS } \\
\text { summary } \\
\text { statistics }\end{array}$ & rs6265 & All & 0.198 & -0.03 to 0.42 & 0.084 & 63030 \\
\hline & & UK Biobank & & & - & - & - & - \\
\hline \multirow[t]{3}{*}{$\begin{array}{l}\text { Smoking } \\
\text { heaviness }\end{array}$} & Neuroticism & UK Biobank & & Non-smokers & 0.004 & -0.02 to 0.03 & 0.745 & 149960 \\
\hline & & & & $\begin{array}{l}\text { Former } \\
\text { smokers }\end{array}$ & 0.011 & -0.02 to 0.04 & 0.472 & 96674 \\
\hline & & & & $\begin{array}{l}\text { Current } \\
\text { smokers }\end{array}$ & 0.038 & -0.02 to 0.10 & 0.234 & 26882 \\
\hline \multirow[t]{2}{*}{$\begin{array}{l}\text { Smoking } \\
\text { cessation }\end{array}$} & Neuroticism & UK Biobank & & Non-smokers & 0.004 & -0.03 to 0.04 & 0.822 & 149960 \\
\hline & & & & Ever smokers & 0.029 & -0.01 to 0.07 & 0.161 & 123556 \\
\hline
\end{tabular}

${ }^{a}$ Two-sample results reported using GWAS summary statistics refer to the causal effect of smoking behaviour on a personality trait. UK Biobank results are effect sizes of the genetic variants for smoking behaviours on personality traits.

Supplementary Table S6). The effect estimates are consistent with those from the two-sample MR and the one-sample analyses. We find no robust evidence of an association with either smoking initiation or cessation, but strong evidence of an association between neuroticism and increased smoking heaviness.

\section{Power calculations}

We performed power calculations for the two-sample MR analyses. Assuming that the genetic instrument for personality traits explains around $1 \%$ of the variation in the exposure and that our sample comprises of around $50 \%$ ever smokers, our sample had approximately $86 \%$ power to detect $25 \%$ greater odds of smoking initiation per each S.D. increase in personality trait. We had around $83 \%$ power to detect a change of 0.15 cigarettes per day or $25 \%$ lower odds of smoking cessation per s.D. increase in personality trait.

\section{Discussion}

We attempted to disentangle the relationship between smoking and the personality traits of neuroticism and extraversion. We found evidence of a modest genetic correlation with both neuroticism and extraversion, which could indicate a causal pathway between personality and smoking behaviours. However, it is not clear in which direction this pathway acts, and there are also alternative explanations such as horizontal pleiotropy (direct genetic effects on multiple traits) (Davey Smith and Hemani, 2014). We used one- and two-sample MR analyses to investigate these pathways in more detail.

Given that available GWAS summary statistics for neuroticism and extraversion are not stratified by smoking status, we initially used two-sample MR approaches to look at the bidirectional association with smoking initiation. This was followed by one-sample analyses using individual-level data from UKB, in instances where these data were available. When looking at the effect of smoking on personality, we found weak evidence that the rs6265 variant for smoking initiation was associated with both lower neuroticism and higher extraversion. When looking in the reverse direction, evidence was stronger. We found some evidence that each additional neuroticism effect allele was associated with smoking an additional 0.07 cigarettes per day, and that each additional extraversion effect allele was associated with $1.5 \%$ greater odds of ever smoking. There was also some suggestion that the extraversion risk score was associated with lower smoking cessation, although the evidence for this was weak.

Estimates from both two-sample MR and one-sample analyses in UKB found a consistent direction of effect, with the smoking initiation instrument (rs6265) associated with a reduction in neuroticism scores, although the evidence for this was weak across both analyses. Although this is a strong instrument for smoking initiation, there could be potential horizontal pleiotropic effects. A recent GWAS investigating risk-taking behaviours used a multitrait analysis of GWAS approach and identified the rs6265 variant as a lead SNP associated with general-risk-tolerance (Linnér et al., 2018). One approach to reduce the potential impact of these effects could be to identify additional strongly associated, but independent variants to include in the smoking initiation instrument by relaxing the $p$ value threshold used to select instruments from the original GWAS, as all horizontal pleiotropic effects would need to operate in the same direction (Gage et al., 2017).

Analyses from personality to smoking behaviours found some evidence of an association between higher neuroticism and smoking heaviness using one-sample MR and two-sample MR after adjusting for horizontal pleiotropy. Both the observational and MR analyses found a stronger effect among current smokers. These findings are consistent with the self-medication hypothesis (Khantzian, 1985, 1997), and in line with previous literature, such as a twin study by Kendler et al. which identified an association with smoking and nicotine dependence (Kendler et al., 1999). It is also possible that this pathway is causal only among smokers who find it hard to quit. Observationally, we see higher levels 
Table 3. Effect of personality traits on smoking using one- and two-sample MR

\begin{tabular}{|c|c|c|c|c|c|c|c|c|}
\hline Exposure & Outcome & Sample & Instrument & $\begin{array}{l}\text { Smoking } \\
\text { status }\end{array}$ & $\mathrm{OR}^{\mathrm{a}}$ & $95 \% \mathrm{Cl}$ & $p$ value & $N$ \\
\hline \multirow[t]{2}{*}{ Neuroticism } & $\begin{array}{l}\text { Smoking } \\
\text { initiation }\end{array}$ & $\begin{array}{l}\text { GWAS } \\
\text { summary } \\
\text { statistics }\end{array}$ & IVW & All & 1.165 & $0.71-1.91$ & 0.499 & 74035 \\
\hline & & UK Biobank & $\begin{array}{l}\text { Unweighted } \\
\text { score }\end{array}$ & All & 1.000 & $0.997-1.003$ & 0.980 & 318985 \\
\hline \multirow[t]{3}{*}{ Extraversion } & $\begin{array}{l}\text { Smoking } \\
\text { initiation }\end{array}$ & $\begin{array}{l}\text { GWAS } \\
\text { summary } \\
\text { statistics }\end{array}$ & IVW & All & 1.733 & $0.37-8.23$ & 0.268 & 74035 \\
\hline & & UK Biobank & $\begin{array}{l}\text { Unweighted } \\
\text { score }\end{array}$ & All & 1.015 & $1.01-1.02$ & $9.6 \times 10^{-7}$ & 332596 \\
\hline & & & & & $\beta^{\mathrm{a}}$ & $95 \% \mathrm{Cl}$ & $p$ value & $N$ \\
\hline \multirow[t]{3}{*}{ Neuroticism } & $\begin{array}{l}\text { Smoking } \\
\text { heaviness }\end{array}$ & $\begin{array}{l}\text { GWAS } \\
\text { summary } \\
\text { statistics }\end{array}$ & IVW & $\begin{array}{l}\text { Ever } \\
\text { smokers }\end{array}$ & 0.050 & -4.11 to 4.21 & 0.979 & 38181 \\
\hline & & UK Biobank & $\begin{array}{l}\text { Unweighted } \\
\text { score }\end{array}$ & $\begin{array}{l}\text { Former } \\
\text { smokers }\end{array}$ & -0.018 & -0.05 to 0.02 & 0.315 & 70909 \\
\hline & & & & $\begin{array}{l}\text { Current } \\
\text { smokers }\end{array}$ & 0.068 & $0.02-0.12$ & 0.009 & 21449 \\
\hline \multirow[t]{4}{*}{ Extraversion } & $\begin{array}{l}\text { Smoking } \\
\text { heaviness }\end{array}$ & $\begin{array}{l}\text { GWAS } \\
\text { summary } \\
\text { statistics }\end{array}$ & IVW & $\begin{array}{l}\text { Ever } \\
\text { smokers }\end{array}$ & 0.017 & -16.33 to 16.37 & 0.997 & 38181 \\
\hline & & UK Biobank & $\begin{array}{l}\text { Unweighted } \\
\text { score }\end{array}$ & $\begin{array}{l}\text { Former } \\
\text { smokers }\end{array}$ & -0.021 & -0.08 to 0.04 & 0.519 & 73967 \\
\hline & & & & $\begin{array}{l}\text { Current } \\
\text { smokers }\end{array}$ & -0.038 & -0.13 to 0.05 & 0.419 & 22340 \\
\hline & & & & & $\mathrm{OR}^{\mathrm{a}}$ & $95 \% \mathrm{Cl}$ & $p$ value & $N$ \\
\hline \multirow[t]{2}{*}{ Neuroticism } & $\begin{array}{l}\text { Smoking } \\
\text { cessation }\end{array}$ & $\begin{array}{l}\text { GWAS } \\
\text { summary } \\
\text { statistics }\end{array}$ & IVW & $\begin{array}{l}\text { Ever } \\
\text { smokers }\end{array}$ & 0.797 & $0.43-1.47$ & 0.423 & 41278 \\
\hline & & UK Biobank & $\begin{array}{l}\text { Unweighted } \\
\text { score }\end{array}$ & $\begin{array}{l}\text { Ever } \\
\text { smokers }\end{array}$ & 0.997 & $0.99-1.00$ & 0.272 & 144119 \\
\hline \multirow[t]{2}{*}{ Extraversion } & $\begin{array}{l}\text { Smoking } \\
\text { cessation }\end{array}$ & $\begin{array}{l}\text { GWAS } \\
\text { summary } \\
\text { statistics }\end{array}$ & IVW & $\begin{array}{l}\text { Ever } \\
\text { smokers }\end{array}$ & 0.586 & $0.07-4.76$ & 0.387 & 41278 \\
\hline & & UK Biobank & $\begin{array}{l}\text { Unweighted } \\
\text { score }\end{array}$ & $\begin{array}{l}\text { Ever } \\
\text { smokers }\end{array}$ & 0.989 & $0.98-1.00$ & 0.057 & 150294 \\
\hline
\end{tabular}

${ }^{\mathrm{a}}$ Two-sample results reported using GWAS summary statistics refer to the causal effect of personality traits on smoking behaviours. UK Biobank results are effect sizes of the genetic instruments for personality traits on smoking behaviours.

of neuroticism among current smokers and stronger evidence of a genetic correlation among this subgroup of individuals, the divergent effects shown in the one-sample MR would be consistent with this interpretation. However, if both neuroticism and smoking heaviness are associated with difficulty in quitting, then it is possible that this association is due to collider bias. These findings could be used to inform existing smoking cessation services, with the type or intensity of intervention tailored according to an individual's level of neuroticism.

We also observed some evidence of an association between extraversion and smoking. Unlike neuroticism, extraversion did not show evidence of a causal relationship with smoking heaviness, but we did find an association with smoking initiation. Although there was no strong evidence of an association when using a two-sample approach, this could be due to a lack of power given that the direction of effect was consistent with that observed in UKB. Using UKB data, there was evidence that individuals with a higher genetic liability for extraversion had greater odds of taking up smoking. One potential mechanism for this is that extraversion could lead to more social contacts and greater susceptibility to peer influences, which are known to be important in smoking initiation (Kobus, 2003; Haas and Schaefer, 2014). These findings could be used to improve existing smoking prevention schemes, for example, tailoring the messages and images used in health warnings.

There are a number of limitations to our analysis that should be considered. First, UKB formed a large part of the discovery cohort for the GWAS of neuroticism. We were therefore unable to use weighted risk scores to assess the association between smoking phenotypes and neuroticism in our one-sample analyses - weights should be identified in independent samples to avoid overfitting the data and introducing bias into effect estimates 
(Hartwig and Davies, 2016). However, we performed sensitivity analyses restricting to individuals who were not included in the discovery samples as well as estimating IVW estimates, and results remained consistent. Second, we were unable to use two-sample methods to assess the association from smoking heaviness and cessation to neuroticism and extraversion because the personality summary statistics were not stratified by smoking status. However, we did investigate the association in both directions for neuroticism when using the UKB data. Both the two-sample and UKB analyses gave consistent results when looking at the neuroticism to smoking initiation relationship. Third, due to the lack of an extraversion phenotype currently available in UKB, we were unable to investigate whether there was evidence of an effect from smoking to extraversion. Fourth, MR analyses can often suffer from a lack of power, with large sample sizes and strong instruments required to detect effects. We have identified genetic variants robustly associated with each trait of interest based on results of large recently published GWAS in order to maximise the strength of our instruments. In this analysis, we have triangulated our findings using a combination of one- and two-sample MR approaches to maximise our power to detect any effect (Lawlor et al., 2017). Fifth, we stratified on smoking status to investigate the association of smoking heaviness and cessation phenotypes. Although this allows us to investigate pleiotropy, there is the potential to introduce collider bias when stratifying on an exposure (Munafò et al., 2018). However, in these stratified analyses, our instruments are principally associated with smoking heaviness and cessation rather than smoking status, so that the risk of collider bias is minimised (Gage et al., 2016).

In conclusion, we found evidence of modest genetic correlation between smoking behaviour and both neuroticism and extraversion. We found some evidence for specific causal pathways from personality to smoking phenotypes - from higher neuroticism to heavier cigarette consumption, and from higher extraversion to greater odds of smoking initiation. Evidence in the alternative direction, suggesting that smoking behaviour influences personality, was weaker. These findings could be used to inform future smoking interventions, for example, tailoring existing smoking cessation schemes to provide people with high or low neuroticism a different type or intensity of service.

Supplementary material. The supplementary material for this article can be found at https://doi.org/10.1017/S0033291718003069.

Author ORCIDs. (D) Hannah M. Sallis http://orcid.org/0000-0002-4793-6290.

Acknowledgements. This research has been conducted using the UK Biobank Resource under application number 9142.

Financial support. This work was supported by the Medical Research Council and the University of Bristol (MC_UU_00011/1, MC_UU_00011/7). MRM and HMS are members of the UK Centre for Tobacco and Alcohol Studies, a UKCRC Public Health Research: Centre of Excellence.

Conflict of interest. None.

\section{References}

Arnold M, Raffler J, Pfeufer A, Suhre K and Kastenmüller G (2015) SNiPA: an interactive, genetic variant-centered annotation browser. Bioinformatics (Oxford, England) 31, 1334-1336.

Bowden J, Davey Smith G and Burgess S (2015) Mendelian randomization with invalid instruments: effect estimation and bias detection through Egger regression. International Journal of Epidemiology 44, 512-525.
Bowden J, Davey Smith G, Haycock PC and Burgess S (2016) Consistent estimation in Mendelian randomization with some invalid instruments using a weighted median estimator. Genetic Epidemiology 40, 304-314.

Bowden J, Del Greco MF, Minelli C, Davey Smith G, Sheehan N and Thompson J (2017) A framework for the investigation of pleiotropy in twosample summary data Mendelian randomization. Wiley-Blackwell Statistics in Medicine 36, 1783-1802.

Bycroft C, Freeman C, Petkova D, Band G, Elliott LT, Sharp K, Motyer A, Vukcevic D, Delaneau O, O'Connell J, Cortes A, Welsh S, McVean G, Leslie S, Donnelly P and Marchini J (2017) Genome-wide genetic data on 500000 UK Biobank participants. BioRxiv, 166298.

Cherry N and Kiernan K (1976) Personality scores and smoking behaviour. A longitudinal study. British Journal of Preventive \& Social Medicine 30, 123-131.

Davey Smith G (2011) Use of genetic markers and gene-diet interactions for interrogating population-level causal influences of diet on health. Genes \& Nutrition 6, 27-43.

Davey Smith G and Ebrahim S (2003) 'Mendelian randomization': can genetic epidemiology contribute to understanding environmental determinants of disease? International Journal of Epidemiology 32, 1-22.

Davey Smith G and Hemani G (2014) Mendelian randomization: genetic anchors for causal inference in epidemiological studies. Human Molecular Genetics 23, R89-R98.

Fluharty M, Taylor AE, Grabski M and Munafò MR (2017) The association of cigarette smoking with depression and anxiety: a systematic review. Nicotine \& Tobacco Research 19, 3-13.

Gage SH, Davey Smith G, Ware JJ, Flint J, Munafò MR and Koifman R (2016) G=E: what GWAS can tell us about the environment. PLoS Genetics 12, e1005765.

Gage SH, Jones HJ, Taylor AE, Burgess S, Zammit S and Munafò MR (2017) Investigating causality in associations between smoking initiation and schizophrenia using Mendelian randomization. Scientific Reports 7, 40653.

Gale CR, Hagenaars SP, Davies G, Hill WD, Liewald DCM, Cullen B, Penninx BW, International Consortium for Blood Pressure GWAS CCA and LG, Boomsma DI, Pell J, McIntosh AM, Smith DJ, Deary IJ and Harris SE (2016) Pleiotropy between neuroticism and physical and mental health: findings from 108038 men and women in UK Biobank. Translational Psychiatry 6, e791.

Haas SA and Schaefer DR (2014) With a little help from my friends? Asymmetrical social influence on adolescent smoking initiation and cessation. Journal of Health and Social Behavior 55, 126-143.

Hakulinen C, Hintsanen M, Munafò MR, Virtanen M, Kivimäki M, Batty GD and Jokela M (2015) Personality and smoking: individualparticipant meta-analysis of nine cohort studies. Addiction 110, 1844-1852.

Hartwig FP and Davies NM (2016) Why internal weights should be avoided (not only) in MR-Egger regression. International Journal of Epidemiology 45, 1676-1678.

Holmes MV, Ala-Korpela M and Davey Smith G (2017) Mendelian randomization in cardiometabolic disease: challenges in evaluating causality. Nature Reviews Cardiology 14, 577-590.

Kendler KS, Neale MC, Kessler RC, Heath AC and Eaves LJ (1993) A longitudinal twin study of personality and major depression in women. Archives of General Psychiatry 50, 853-862.

Kendler KS, Neale MC, Sullivan P, Corey LA, Gardner CO and Prescott CA (1999) A population-based twin study in women of smoking initiation and nicotine dependence. Psychological Medicine 29, 299-308.

Khantzian EJ (1985) The self-medication hypothesis of addictive disorders: focus on heroin and cocaine dependence. American Journal of Psychiatry 142, 1259-1264.

Khantzian EJ (1997) The self-medication hypothesis of substance use disorders: a reconsideration and recent applications. Harvard Review of Psychiatry 4, 231-244.

Kobus K (2003) Peers and adolescent smoking. Addiction 98, 37-55.

Lawlor DA, Tilling K and Davey Smith G (2017) Triangulation in aetiological epidemiology. International Journal of Epidemiology 45, 1866-1886.

Linnér RK, Biroli P, Kong E, Meddens SFW, Wedow R, Fontana MA, Lebreton M, Abdellaoui A, Hammerschlag AR, Nivard MG, Okbay A, 
Rietveld CA, Timshel PN, Tino SP, Trzaskowski M, de Vlaming R, Zünd CL, Bao Y, Buzdugan L, Caplin AH, Chen C-Y, Eibich P, Fontanillas P, Gonzalez JR, Joshi PK, Karhunen V, Kleinman A, Levin RZ, Lill CM, Meddens GA, Muntané G, Sanchez-Roige S, van Rooij FJ, Taskesen E, Wu Y, Zhang F, Team 23andMe Research, Consortium Eqtl, Consortium IC, Consortium PG, Consortium SSGA, Auton A, Boardman JD, Clark DW, Conlin A, Dolan CC, Fischbacher U, Groenen PJ, Harris KM, Hasler G, Hofman A, Ikram MA, Jain S, Karlsson R, Kessler RC, Kooyman M, MacKillop J, Männikkö M, Morcillo-Suarez C, McQueen MB, Schmidt KM, Smart MC, Sutter M, Thurik AR, Uitterlinden AG, White J, de Wit H, Yang J, Bertram L, Boomsma D, Esko T, Fehr E, Hinds DA, Johannesson M, Kumari M, Laibson D, Magnusson PK, Meyer MN, Navarro A, Palmer AA, Pers TH, Posthuma D, Schunk D, Stein MB, Svento R, Tiemeier H, Timmers PR, Turley P, Ursano RJ, Wagner GG, Wilson JF, Gratten J, Lee JJ, Cesarini D, Benjamin DJ, Koellinger P and Beauchamp JP (2018) Genome-wide study identifies 611 loci associated with risk tolerance and risky behaviors. BioRxiv, 261081.

Lo M-T, Hinds DA, Tung JY, Franz C, Fan C-C, Wang Y, Smeland OB, Schork A, Holland D, Kauppi K, Sanyal N, Escott-Price V, Smith DJ, O'Donovan M, Stefansson H, Bjornsdottir G, Thorgeirsson TE, Stefansson K, McEvoy LK, Dale AM, Andreassen OA and Chen C-H (2017) Genome-wide analyses for personality traits identify six genomic loci and show correlations with psychiatric disorders. Nature Genetics 49, 152-156.

Malouff JM, Thorsteinsson EB and Schutte NS (2006) The five-factor model of personality and smoking: a meta-analysis. Journal of Drug Education 36, $47-58$

Mitchell R, Hemani G, Dudding T and Paternoster L (2017) UK Biobank Genetic Data: MRC-IEU Quality Control, Version 1. doi: https://doi.org/ 10.5523/bris.3074krb6t2fri29yh2b03×3wxj.

Munafò MR and Araya R (2010) Cigarette smoking and depression: a question of causation. British Journal of Psychiatry 196, 425-426.

Munafò MR, Zetteler JI and Clark TG (2007) Personality and smoking status: a meta-analysis. Nicotine \& Tobacco Research 9, 405-413.

Munafò MR, Tilling K, Taylor AE, Evans DM and Davey Smith G (2018) Collider scope: when selection bias can substantially influence observed associations. International Journal of Epidemiology 47, 226-235.

Neale BM, Sullivan PF and Kendler KS (2005) A genome scan of neuroticism in nicotine dependent smokers. American Journal of Medical Genetics Part B: Neuropsychiatric Genetics 132B, 65-69.

Okbay A, Baselmans BML, De Neve J-E, Turley P, Nivard MG, Fontana MA, Meddens SFW, Linnér RK, Rietveld CA, Derringer J, Gratten J, Lee JJ, Liu JZ, de Vlaming R, Ahluwalia TS, Buchwald J, Cavadino A, Frazier-Wood AC, Furlotte NA, Garfield V, Geisel MH, Gonzalez JR, Haitjema S, Karlsson R, van der Laan SW, Ladwig K-H, Lahti J, van der Lee SJ, Lind PA, Liu T, Matteson L, Mihailov E, Miller MB, Minica CC, Nolte IM, Mook-Kanamori D, van der Most PJ, Oldmeadow C, Qian Y, Raitakari O, Rawal R, Realo A, Rueedi R, Schmidt B, Smith AV, Stergiakouli E, Tanaka T, Taylor K, Wedenoja J, Wellmann J, Westra H-J, Willems SM, Zhao W, Amin N, Bakshi A, Boyle PA, Cherney S, Cox SR, Davies G, Davis OSP, Ding J, Direk N, Eibich P, Emeny RT, Fatemifar G, Faul JD, Ferrucci L, Forstner A, Gieger C, Gupta R, Harris TB, Harris JM, Holliday EG, Hottenga J-J, De Jager PL, Kaakinen MA, Kajantie E, Karhunen V, Kolcic I, Kumari M, Launer LJ, Franke L, Li-Gao R, Koini M, Loukola A, Marques-Vidal P, Montgomery GW, Mosing MA, Paternoster L, Pattie A, Petrovic KE, Pulkki-Råback L, Quaye L, Räikkönen K, Rudan I, Scott RJ, Smith JA, Sutin AR, Trzaskowski M, Vinkhuyzen AE, Yu L, Zabaneh D, Attia JR, Bennett DA, Berger K, Bertram L, Boomsma DI, Snieder H, Chang SC, Cucca F, Deary IJ, van Duijn CM, Eriksson JG, Bültmann U, de Geus EJ, Groenen PJ, Gudnason V, Hansen T, Hartman CA, Haworth CM, Hayward C, Heath AC, Hinds DA, Hyppönen E, Iacono WG, Järvelin MR, Jöckel KH, Kaprio J, Kardia SL, Keltikangas-Järvinen L, Kraft P, Kubzansky LD, Lehtimäki T, Magnusson PK, Martin NG, McGue M, Metspalu A, Mills M, de Mutsert R, Oldehinkel AJ, Pasterkamp G, Pedersen NL, Plomin R, Polasek O, Power C, Rich SS, Rosendaal FR, den Ruijter HM, Schlessinger D, Schmidt H, Svento R, Schmidt R, Alizadeh BZ, Sørensen TI, Spector TD, Starr JM, Stefansson K, Steptoe A, Terracciano A, Thorsteinsdottir U, Thurik AR, Timpson NJ, Tiemeier H, Uitterlinden AG, Vollenweider P, Wagner GG, Weir DR, Yang J, Conley DC, Smith GD, Hofman A, Johannesson M, Laibson DI, Medland SE, Meyer MN, Pickrell JK, Esko T, Krueger RF, Beauchamp JP, Koellinger PD, Benjamin DJ, Bartels $M$ and Cesarini D (2016) Genetic variants associated with subjective well-being, depressive symptoms, and neuroticism identified through genome-wide analyses. Nature Genetics 48, 624-633.

Sallis H, Steer C, Paternoster L, Davey Smith G and Evans J (2014) Perinatal depression and omega-3 fatty acids: a Mendelian randomisation study. Journal of Affective Disorders 166, 124-131.

Smith DJ, Nicholl BI, Cullen B, Martin D, Ul-Haq Z, Evans J, Gill JMR, Roberts B, Gallacher J, Mackay D, Hotopf M, Deary I, Craddock N and Pell JP (2013) Prevalence and characteristics of probable major depression and bipolar disorder within UK Biobank: cross-sectional study of 172,751 participants. PLoS ONE 8, e75362.

Sudlow C, Gallacher J, Allen N, Beral V, Burton P, Danesh J, Downey P, Elliott P, Green J, Landray M, Liu B, Matthews P, Ong G, Pell J, Silman A, Young A, Sprosen T, Peakman T, Collins R, Clayton D, McKeigue P, Willett W, Blot W, Colditz G, Folsom A, Henderson B, Stampfer M, Collins F, Manolio T, Doll R, Peto R, Ollier W, Sprosen T, Peakman T, Burton P, Hansell A, Fortier I, Manolio T, Khoury M, Hattersley A, McCarthy M, Collins R, Elliott P, Peakman T, Liu B, Young H, Crowe F, Benson V, Spencer E, Clarke R, Shipley M, Lewington S, Youngman L, Collins R, Pell J, Valentine J, Inskip H, Downey P, Peakman T, Manolio T, Barbour V, Manolio T and Collins R (2015) UK biobank: an open access resource for identifying the causes of a wide range of complex diseases of middle and old age. PLoS Medicine 12, e1001779.

Taylor AE, Fluharty ME, Bjørngaard JH, Gabrielsen ME, Skorpen F, Marioni RE, Campbell A, Engmann J, Mirza SS, Loukola A, Laatikainen T, Partonen T, Kaakinen M, Ducci F, Cavadino A, Husemoen LLN, Ahluwalia TS, Jacobsen RK, Skaaby T, Ebstrup JF, Mortensen EL, Minica CC, Vink JM, Willemsen G, Marques-Vidal P, Dale CE, Amuzu A, Lennon LT, Lahti J, Palotie A, Räikkönen K, Wong A, Paternoster L, Wong AP-Y, Horwood LJ, Murphy M, Johnstone EC, Kennedy MA, Pausova Z, Paus T, Ben-Shlomo Y, Nohr EA, Kuh D, Kivimaki M, Eriksson JG, Morris RW, Casas JP, Preisig M, Boomsma DI, Linneberg A, Power C, Hyppönen E, Veijola J, Jarvelin M-R, Korhonen T, Tiemeier H, Kumari M, Porteous DJ, Hayward C, Romundstad PR, Davey Smith G and Munafò MR (2014) Investigating the possible causal association of smoking with depression and anxiety using Mendelian randomisation meta-analysis: the CARTA consortium. BMJ Open 4, e006141.

Terracciano A and Costa Jr PT (2004) Smoking and the five-factor model of personality. Addiction $99,472-481$.

Tobacco and Genetics Consortium (2010) Genome-wide meta-analyses identify multiple loci associated with smoking behavior. Nature Genetics 42, 411-417.

van den Berg SM, de Moor MHM, Verweij KJH, Krueger RF, Luciano M, Arias Vasquez A, Matteson LK, Derringer J, Esko T, Amin N, Gordon SD, Hansell NK, Hart AB, Seppälä I, Huffman JE, Konte B, Lahti J, Lee M, Miller M, Nutile T, Tanaka T, Teumer A, Viktorin A, Wedenoja J, Abdellaoui A, Abecasis GR, Adkins DE, Agrawal A, Allik J, Appel K, Bigdeli TB, Busonero F, Campbell H, Costa PT, Davey Smith G, Davies G, de Wit H, Ding J, Engelhardt BE, Eriksson JG, Fedko IO, Ferrucci L, Franke B, Giegling I, Grucza R, Hartmann AM, Heath AC, Heinonen K, Henders AK, Homuth G, Hottenga J-J, Iacono WG, Janzing J, Jokela M, Karlsson R, Kemp JP, Kirkpatrick MG, Latvala A, Lehtimäki T, Liewald DC, Madden PAF, Magri C, Magnusson PKE, Marten J, Maschio A, Mbarek H, Medland SE, Mihailov E, Milaneschi Y, Montgomery GW, Nauck M, Nivard MG, Ouwens KG, Palotie A, Pettersson E, Polasek O, Qian Y, Pulkki-Råback L, Raitakari OT, Realo A, Rose RJ, Ruggiero D, Schmidt CO, Slutske WS, Sorice R, Starr JM, St Pourcain B, Sutin AR, Timpson NJ, Trochet H, Vermeulen S, Vuoksimaa E, Widen E, Wouda J, Wright MJ, Zgaga L, Porteous D, Minelli A, Palmer AA, 
Rujescu D, Ciullo M, Hayward C, Rudan I, Metspalu A, Kaprio J, Deary IJ, Räikkönen K, Wilson JF, Keltikangas-Järvinen L, Bierut LJ, Hettema JM, Grabe HJ, Penninx BWJH, van Duijn CM, Evans DM, Schlessinger D, Pedersen NL, Terracciano A, McGue M, Martin NG and Boomsma DI (2016) Meta-analysis of genome-wide association studies for extraversion: findings from the genetics of personality consortium. Behavior Genetics 46, 170-182.

World Health Organisation (2002) The World Health Report 2002 - Reducing Risks, Promoting Healthy Life. Geneva, Switzerland: World Health Organization.

Wray NR, Ripke S, Mattheisen M, Trzaskowski M, Byrne EM, Abdellaoui A, Adams MJ, Agerbo E, Air TM, Andlauer TMF, Bacanu S-A, Bækvad-Hansen M, Beekman AFT, Bigdeli TB, Binder EB, Blackwood DRH, Bryois J, Buttenschøn HN, Bybjerg-Grauholm J, Cai N, Castelao E, Christensen JH, Clarke T-K, Coleman JIR, Colodro-Conde L, Couvy-Duchesne B, Craddock N, Crawford GE, Crowley CA, Dashti HS, Davies G, Deary IJ, Degenhardt F, Derks EM, Direk N, Dolan CV, Dunn EC, Eley TC, Eriksson N, Escott-Price V, Kiadeh FHF, Finucane HK, Forstner AJ, Frank J, Gaspar HA, Gill M, Giusti-Rodríguez P, Goes FS, Gordon SD, Grove J, Hall LS, Hannon E, Hansen CS, Hansen TF, Herms S, Hickie IB, Hoffmann P, Homuth G, Horn C, Hottenga J-J, Hougaard DM, Hu $M$, Hyde $C L$, Ising $M$, Jansen $R$, Jin $F$, Jorgenson E, Knowles JA, Kohane IS, Kraft J, Kretzschmar WW, Krogh J, Kutalik Z, Lane JM, Li Y, Li Y, Lind PA, Liu X, Lu L, MacIntyre DJ, MacKinnon DF, Maier RM, Maier W, Marchini J, Mbarek H, McGrath P, McGuffin P, Medland SE, Mehta D, Middeldorp CM, Mihailov E, Milaneschi Y, Milani L, Mill J,
Mondimore FM, Montgomery GW, Mostafavi S, Mullins N, Nauck M, Ng B, Nivard MG, Nyholt DR, O'Reilly PF, Oskarsson H, Owen MJ, Painter JN, Pedersen CB, Pedersen MG, Peterson RE, Pettersson E, Peyrot WJ, Pistis G, Posthuma D, Purcell SM, Quiroz JA, Qvist P, Rice JP, Riley BP, Rivera M, Saeed Mirza S, Saxena R, Schoevers R, Schulte EC, Shen L, Shi J, Shyn SI, Sigurdsson E, Sinnamon GBC, Smit JH, Smith DJ, Stefansson H, Steinberg S, Stockmeier CA, Streit F, Strohmaier J, Tansey KE, Teismann H, Teumer A, Thompson W, Thomson PA, Thorgeirsson TE, Tian C, Traylor M, Treutlein J, Trubetskoy V, Uitterlinden AG, Umbricht D, Van der Auwera S, van Hemert AM, Viktorin A, Visscher PM, Wang Y, Webb BT, Weinsheimer SM, Wellmann J, Willemsen G, Witt SH, Wu Y, Xi HS, Yang J, Zhang F, Arolt V, Baune BT, Berger K, Boomsma DI, Cichon S, Dannlowski U, de Geus ECJ, DePaulo JR, Domenici E, Domschke K, Esko T, Grabe HJ, Hamilton SP, Hayward C, Heath AC, Hinds DA, Kendler KS, Kloiber S, Lewis G, Li QS, Lucae S, Madden PFA, Magnusson PK, Martin NG, McIntosh AM, Metspalu A, Mors O, Mortensen PB, Müller-Myhsok B, Nordentoft M, Nöthen MM, O'Donovan MC, Paciga SA, Pedersen NL, Penninx BWJH,Perlis RH, Porteous DJ, Potash JB, Preisig M, Rietschel M, Schaefer C, Schulze TG, Smoller JW, Stefansson K, Tiemeier H, Uher R, Völzke H, Weissman MM, Werge T, Winslow AR, Lewis CM, Levinson DF, Breen G, Børglum AD and Sullivan PF (2018) Genome-wide association analyses identify 44 risk variants and refine the genetic architecture of major depression. Nature Genetics 50, 668-681.

Yang J, Lee SH, Goddard ME and Visscher PM (2011) GCTA: a tool for genome-wide complex trait analysis. American Journal of Human Genetics 88, 76-82. 